Journal of Life Economics

Cilt / Volume 6, Say1 / Issue 1, 2019, pp. 1-10

E - ISSN: 2148-4139

URL: http://www.ratingacademy.com.tr/ojs/index.php/jlecon

DOİ: $10.15637 /$ jlecon.6.001

Araştırma Makalesi/Research Article

\title{
ASYMMETRIC PANEL CAUSALITY TEST WITH AN APPLICATION TO THE IMPACT OF CLIMATE CHANGE ON FINANCIAL RISK§
}

\author{
Ünzüle KURT* \& Feyza BALAN** \\ *Assist. Prof. Dr., Çanakkale Onsekiz Mart University, Faculty of Applied Sciences at Biga, \\ Department of Economics, TURKEY,E-mail: unzulekurt@comu.edu.tr \\ ORCID ID: https://orcid.org/0000-0003-3406-1269 \\ **Assoc. Prof. Dr., Çanakkale Onsekiz Mart University, Faculty of Economics and Administrative \\ Sciences, Department of Banking and Finance, TURKEY, E-mail: feyzarica@ gmail.com \\ ORCID ID: https://orcid.org/0000-0002-5552-347X
}

Received: 29 November 2018; Accepted: 21 January 2019

\begin{abstract}
Climate change which caused to dramatic economic impact is a key issue for the world in the 21 st century. Using data for Portugal, Ireland, Italy and Spain (PIIGS) countries over the years 19902009, this study investigates the causal relationship from climate change to financial risk/stability via Hatemi-J asymmetric causality test that separates positive and negative shocks in analysis. As a result of this study, both positive and negative shocks existed for Ireland, causality from climate change to financial risk emerged for Spain in only negative shocks. In addition, the results showed that a positive shock in climate change cause a negative shock in financial stability. In the cases of Greece and Portugal none of the causal relationships cannot be proved.
\end{abstract}

Keywords: asymmetric panel causality test, climate change, financial risk.

JEL Codes: C33, G32, Q54

\section{INTRODUCTION}

The physical climate system that is associated with the earth's atmosphere, land surfaces and oceans, along with the snow and ice is constantly changing. Not only do changes to each component of the system influence the risk of natural catastrophes, but the interactions between them bring about an inherent uncertainty surrounding how climate will evolve in the future (Dailey et al. 2009).

Together with this uncertainty, by the rapid development of technology and hence the increasing significance of energy consumption, the effect of environmental issues on financial institutions has become one of the most popular issues since the 1980s. Especially, financial 
regulators and policy makers have focused on the climate change and its financial impacts. The fact that climate change risk was also on the agenda of the G7 summit, was held in Schloss Elmau in June 2015 can be illustrated as an example to its popularity.

Climate change has caused to dramatic economic impact. It has altered the availability of and demand for resources, supply and demand for products and services, the performance of physical assets, and the need for innovation. Failure to consider climate change in investment strategies can undermine projected financial returns and affect the non-financial risk management of institutions, particularly on development, environmental, and social issues (Stenek et al. 2009).

This study has focused especially potential impacts of climate change on agriculture and forestry. For the insurance industry, offering financial protection against extreme events, climate change could increase cost of agriculture and forestry cover by increasing the severity of extreme weather events such as heathwaves, storms and floods (ABI 2005).

Within this overall framework, the aim of this study is to investigate the presence of the asymmetric causal relationships between financial risk and the climate change, is proxied by energy use in agriculture and forestry in Portugal, Ireland, Italy, Greece and Spain that are denoted as PIIGS and that were also unable to finance their government debt or to bail out overindebted banks on their own during the debt crisis. Whereas no such analysis exists yet, the topic is now being raised as a topic on the agenda of macro prudential authorities.

In the rest of the paper, Section 2 outlines theoretical background of the relationship of financial risk-climate change. The data, the empirical methodology employed and the empirical findings are presented in Section 3. The final section provides concluding remarks.

\section{THEORETICAL BACKGROUND}

Financial risk is defined to encompass both individual financial institutions and a systemic financial crisis. Systemic financial risk is the risk that an event will trigger a loss of economic value or confidence in, and attendant increases in uncertainly about, a substantial portion of the financial system that is serious enough to quite probably have significant adverse effects on the real economy. The adverse real economic effects from systemic problems are generally seen as arising from disruptions to the payment system, to credit flows, and from the destruction of asset values (BIS 2001).

Climate change can be defined as the changes in climate (i.e. regional temperature, precipitation, extreme weather, etc.) triggered by increase in the greenhouse effect. Chenet et al. (2015) divides into two categories climate change related risks. These are physical climate risks and carbon risks. Physical changes in climate can lead to both gradual modifications of climate patterns and extreme weather events. These are likely to change the supply and demand dynamic of many industries and hence lead to physical damages to assets. So, these changes are expected to give rise to both adaptation costs and economic loss of value. This situation can be defined as physical climate risk. Alternatively, carbon risks are defined as the family of risks associated with the transition to a low-carbon economy. The transition to a low-carbon economy will alter the financial viability of a part of the capital stock and business models and will greatly impact investments and financial opportunity.

On the other hand, climate change resulting from human activities such as deforestation and the burning of fossil fuels for energy has been identified as a risk that existing reporting standards have yet to adequately measure and communicate to investors. In response to this concern, a climate change risk disclosure regime has emerged, defined by a range of voluntary, regulatory and accounting governance initiatives. Although the regime is a promising development involving a range of influential financial constituencies, it is highly fragmented 
and lacks the coordination and enforcement necessary to adequately measure and communicate the impacts of climate change on financial markets (Thistlethwaite 2015).

Moreover, financial performance and conditions for both equity and debt may be weakened by a number of factors as a related climate change. These factors can be ranged as the following (Stenek et al. 2009):

- Both supply and demand in market conditions that can be sensitive to climate factors have important effects in determining of future prices. So, future climate-driven changes in prices may affect the competitiveness of investments. Alternatively, due to changes in the price, operating costs and maintenance costs may increase.

- Changing climate conditions also may negatively influence the efficiency and performance of assets and equipment.

- Changing climate conditions may increase asset depreciation rates. The rates currently used for accounting purposes generally reflect historical experience, but the effective depreciation rates of assets due to climate change may be considerably higher. So, financial models may overestimate value of physical assets. Faster capital depreciation could mean that assets need replacing more frequently, in turn, negatively affecting projected cash flows.

- Country risk may be aggravated by climate change impacts, particularly in economies where GDP is reliant on scarce water resources, or in smaller economies that are more vulnerable to catastrophic climate events. Especially, there have been studies which show that rising temperatures in some regions are associated with increased risk of armed conflicts.

The following section will elaborate on the methodology to be used in this study along with a description of the data. The methodology includes testing for homogeneity, crosssectional independence, unit root, noncausality and a panel estimation approach to determine asymmetric causal relationships approach in our panel data.

\section{EMPIRICAL ANALYSIS}

In this paper, it was attempted to carry out an econometric model to illustrate the causal relationships between financial risk and climate change, is proxied by energy used in agriculture and forestry in Portugal, Ireland, Italy, Greece and Spain. Regarding the following methodology, it was used the asymmetric panel causality test suggested by Hatemi-J (2011) in order to draw empirical support if there is a specific direction from climate change to financial risk.

\subsection{Data}

Financial risk $(F R)$. Financial risk data are from the International Country Risk Guide (ICRG) (2010). These data are available from 1984 onwards.

PRS Group (2005) has provided information on 5 financial risk indicators. Our main indicator of financial risk is the ICRG financial risk index. This index captures countries' overall financial risk. The index includes scores on foreign debt as a percentage of GDP; foreign debt service as a percentage of exports of goods and services; current account as a percentage of exports of goods and services, net international liquidity and exchange rate stability.

The financial risk index ranges from 0 to 50 . If the points are in the $0.0 \%-24.5 \%$ range it is very high risk; in the $25.0 \%-29.9 \%$ range high risk; in the $30.0 \%-34.9 \%$ range moderate risk; in the $35.0 \%-39.9 \%$ range low Risk; and in the $40.0 \%$ or more range very low risk. 
Climate Change $(C C)$. Energy used in agriculture and forestry data is used as a proxy variable of Climate Change. Agriculture consumes energy directly for crop and livestock production (machinery, etc) but also indirectly through fertilizers and pesticides. Agriculture also produces energy as biofuels and biomass production. As an energy user, Agriculture contributes to global warming (mainly through $\mathrm{CO}_{2}$ emissions, but also $\mathrm{CH}_{4}$ and $\mathrm{N}_{2} \mathrm{O}$ emissions), air pollution (mainly through $\mathrm{NO}_{\mathrm{x}}$ and $\mathrm{SO}_{2}$ emissions) and to the depletion of fossil energy resources. Important energy users are glasshouse horticulture, floriculture and dairy production (FAO, 2014). The data are from Food and Agriculture Organization of The United Nations (FAO), 2014.

Figure 1 shows the trend of financial risk and energy used in agriculture and forestry as a proxy variable of climate change for PIIGS countries for the period 1990 to 2009. Table 1 presents descriptive statistics of FR and $\mathrm{CC}$, indicating financial risk and energy used in agriculture and forestry, respectively. According to dataset, Greece and Italy have the highest of energy used in agriculture and forestry and financial stability, respectively, while Greece and Portugal have the lowest financial stability and energy used in agriculture and forestry, respectively.

Figure 1. Financial risk and Energy used in agriculture and forestry of the PIIGS for 19902009

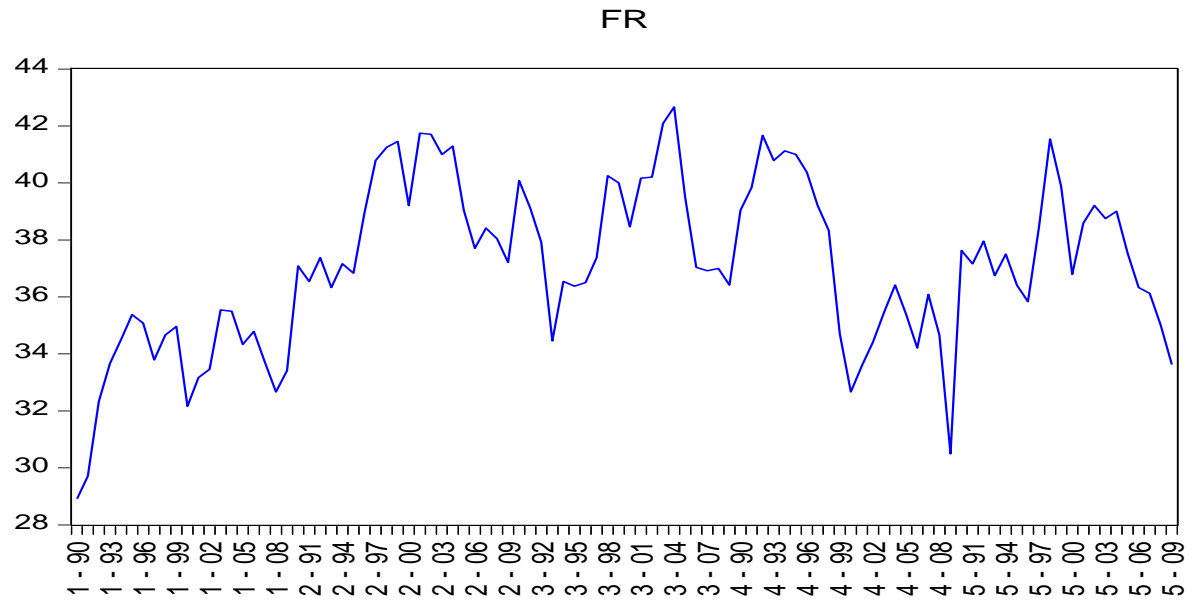

Source: ICRG, 2014

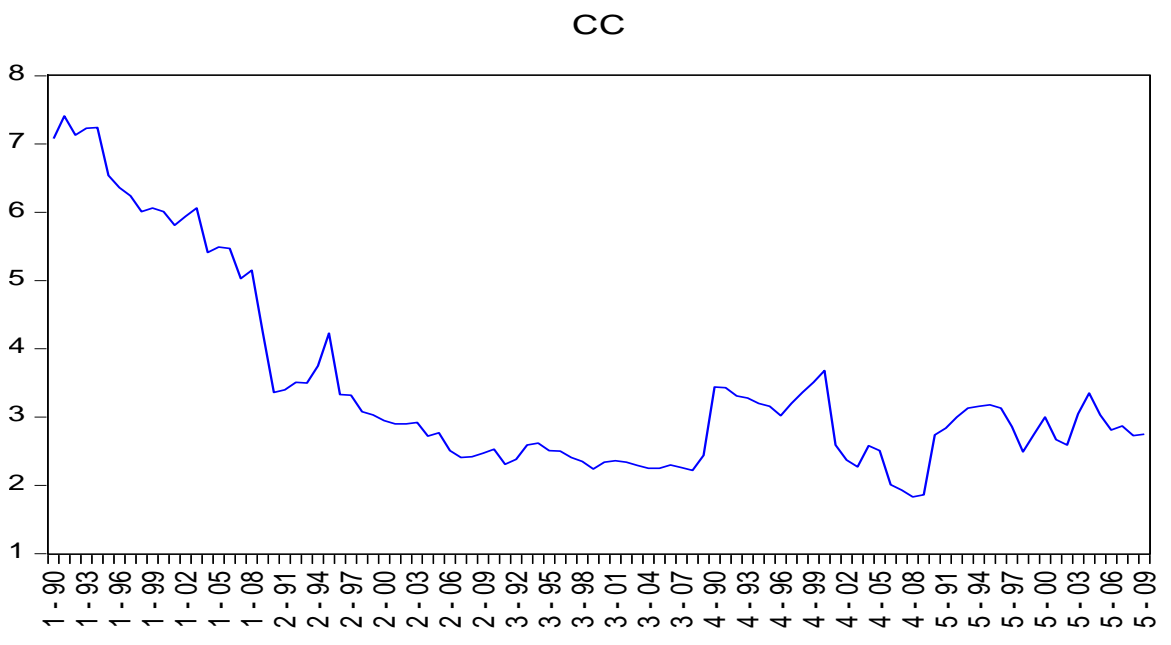

Source: FAO, 2014

Table 1. Descriptive statistics 


\begin{tabular}{|l|c|c|}
\hline & FR & CC \\
\hline Mean & 37,095 & 3,455 \\
\hline Median & 37,062 & 2,975 \\
\hline Maximum & 42,666 & 7,410 \\
\hline Minimum & 28,916 & 1,830 \\
\hline Std. Dev. & 2,911 & 1,442 \\
\hline
\end{tabular}

Source: Authors' estimations

\subsection{Method}

After obtaining the descriptive statistics, we test the existence of cross-sectional dependence across the PIIGS countries. Pesaran (2006) showed that ignoring cross-section dependency leads to substantial bias and size distortions in estimation of the relationship between two variables. Hence, we used Breusch and Pagan (1980)'s Lagrange multiplier test statistic, $\mathrm{LM}_{\mathrm{BP}}$, in order to analyze whether the four countries are cross sectionally dependent.

In the analysis of panel data, the other issue to consider is the testing of slope homogeneity. The homogeneity of the estimated coefficients for each individual in the panel is investigated through Pesaran and Yamagata's (2008) homogeneity tests in this study.

Having found the presence of cross-sectional independence and the slope heterogeneity in the panel, we control whether there exists unit root in the series in order to get unbiased estimations. We used the approaches of Im et al. (2003, henceforth IPS), Maddala and Wu (1999, henceforth MW), Choi (2001) as the panel unit root tests. The IPS test allows for residual serial correlation and heterogeneity of the dynamics and error variances across units. IPS compute separate unit root tests for the $\mathrm{N}$ cross-section units. IPS defines their t-bar statistics as a simple average of the individual ADF statistics. The approaches of MW and Choi are based on a combination of the $\mathrm{p}$-values of the test statistics for a unit root in each cross-sectional unit.

Finally, to show the causal relationships between financial risk and climate change we used the asymmetric panel causality test proposed by Hatemi-J (2011). Because, the Granger causality testing is based on the supposition that the causal impact of positive shocks is of the same absolute magnitude as the causal impact of negative ones. Thus, the Granger causality approach does neglect potential asymmetric causal impacts (Hatemi-J 2011). But, it is wellknown that many markets are characterized by the asymmetric information property (Akerlof 1970, Spence 1973, Stiglitz 1974). Hence, it has become so important whether the asymmetric property in the causality testing is taken into account or not (Granger and Yoon 2002; HatemiJ et al. 2014).

Hatemi-J (2012) suggests that tests for causality should be implemented by using cumulative sums of positive and negative components of the underlying variables in the causality testing for allowing asymmetry. In this approach, it is assumed that variables such as $\mathrm{y}_{1}$ and $\mathrm{y}_{2}$ are integrated of the first degree, with the corresponding solution obtained the recursive method as the following:

$$
\begin{aligned}
& y_{1, t}=y_{1, t-1}+e_{1, t}=y_{1,0}+\sum_{j=1}^{t} e_{1, j} \\
& y_{2, t}=y_{2, t-1}+e_{2, t}=y_{2,0}+\sum_{j=1}^{t} e_{2, j}
\end{aligned}
$$


where $y_{1,0}$ and $y_{2,0}$ are representing the initial values and $\mathrm{n}$ is the number of crosssection within the panel system and e is the white noise error term.

The positive and negative shocks can be defined as the following: $e_{1, \mathrm{j}}^{+}:=\max \left(e_{1, \mathrm{j}}, 0\right), e_{2, \mathrm{j}}^{+}:=\max \left(e_{2, \mathrm{j}}, 0\right), e_{1, \mathrm{j}}^{-}:=\min \left(e_{1, \mathrm{j}}, 0\right), e_{2, \mathrm{j}}^{-}:=\min \left(e_{2, \mathrm{j}}, 0\right)$.

By using these definitions, Hatemi-J (2011) constructed the cumulative sums of the shocks, which are denoted $y_{1, t}^{+}, \mathrm{y}_{2, t}^{+}, \mathrm{y}_{1, t}^{-}, \mathrm{y}_{2, t}^{-}$, as the following:

$$
\begin{aligned}
& y_{1, t}^{+}=\mathrm{y}_{1,0}^{+}+\mathrm{e}_{1, j}^{+}=\mathrm{y}_{1,0}+\sum_{\mathrm{j}=1}^{\mathrm{t}} \mathrm{e}_{1, j}^{+} ; y_{2, t}^{+}=\mathrm{y}_{2,0}^{+}+\mathrm{e}_{2, j}^{+}=\mathrm{y}_{2,0}+\sum_{\mathrm{j}=1}^{\mathrm{t}} \mathrm{e}_{2, j}^{+} \\
& y_{1, t}^{-}=\mathrm{y}_{1,0}^{-}+\mathrm{e}_{1, j}^{-}=\mathrm{y}_{1,0}+\sum_{\mathrm{j}=1}^{\mathrm{t}} \mathrm{e}_{1, j}^{-} ; y_{2, t}^{-}=\mathrm{y}_{2,0}^{-}+\mathrm{e}_{2, j}^{-}=\mathrm{y}_{2,0}+\sum_{\mathrm{j}=1}^{\mathrm{t}} \mathrm{e}_{2, j}^{-}
\end{aligned}
$$

Hatemi-J (2011)'s panel causality test is conducted within a vector autoregressive seemingly unrelated regression model of order $\mathrm{k}$ :

$$
\left[\begin{array}{c}
y_{1, t}^{+} \\
y_{2, t}^{+}
\end{array}\right]=\left[\begin{array}{l}
\beta_{10} \\
\gamma_{10}
\end{array}\right]+\left[\begin{array}{ll}
\sum_{r=1}^{k} \beta_{1, r} & \sum_{r=1}^{k} \beta_{2, r} \\
\sum_{r=1}^{k} \gamma_{1, r} & \sum_{r=1}^{k} \gamma_{2, r}
\end{array}\right] \cdot\left[\begin{array}{c}
y_{1, t-r}^{+} \\
y_{2, t-r}^{+}
\end{array}\right]+\left[\begin{array}{c}
\varepsilon_{1, j}^{+} \\
\varepsilon_{2, j}^{+}
\end{array}\right]
$$

the error terms in the system are defined by $\varepsilon_{1 j}^{+}$and $\varepsilon_{2 j}^{+}$. $\mathrm{k}$ is the lag order minimizing a panel version of an information criterion. The null hypothesis of the test is as follows:

$H_{0}: \beta_{2, r}=0, \forall_{r}$ where $\mathrm{r}=1, \ldots, \mathrm{k}$. This hypothesis suggests that $y_{2, t}^{+}$does not cause $y_{1, t}^{+}$for the cross-sectional unit $\mathrm{j}$ in the panel and this hypothesis is tested by using a Wald test according to Hatemi-J (2011). In addition, other combinations of $\left(y_{1, t}^{-}, \mathrm{y}_{2, t}^{+}\right),\left(y_{1, t}^{+}, \mathrm{y}_{2, t}^{-}\right)$or $\left(y_{1, t}^{-}, \mathrm{y}_{2, t}^{-}\right)$are constructed by a similar way.

\subsection{The Empirical Findings}

Firstly, Breusch and Pagan (1980)'s cross-section LM testing was employed since number of cross-section observation (5) is smaller than number of time series observation (20). Table 2 reports $\mathrm{LM}_{\mathrm{BP}}$ test results confirming the presence of the cross sectional independence in the panel series at the $1 \%$ significance level. 
Table 2. Results for Cross-sectional Dependence

\begin{tabular}{|l|l|l|}
\hline & \multicolumn{2}{|c|}{ LM $_{\text {BP }}$ test } \\
\hline Variable & Test Statistic & P-value \\
\hline FR & 15,278 & 0,122 \\
\hline CC & 15,023 & 0,131 \\
\hline
\end{tabular}

Source: Authors' estimations

The results for the slope homogeneity tests are illustrated in Table 3. According to Table 3 , the homogeneity tests can be rejected the equality hypothesis, which supports that the slope coefficients are homogeneous. Hence, homogeneity restriction on the variable of interest results should not be imposed when panel unit root testing and panel causality analysis are performed. Otherwise, it can be obtain misleading inferences.

Table 3. Results for Slope Homogeneity

\begin{tabular}{|l|c|c|c|c|}
\hline \multirow{3}{*}{$F R_{i t}=\partial_{0}+\partial_{i} \cdot C C_{i t}+e_{i t}$} & $\begin{array}{c}\bigotimes_{0} \\
\text { test } \\
\text { statistic }\end{array}$ & $\begin{array}{c}\text { P. } \\
\text { value }\end{array}$ & $\begin{array}{c}\&_{a d j} \\
\text { test } \\
\text { statistic }\end{array}$ & $\begin{array}{c}\text { P. } \\
\text { value }\end{array}$ \\
\cline { 2 - 5 } & $3,145^{* * *}$ & 0,001 & $3,397 * * *$ & 0,000 \\
\hline
\end{tabular}

*** indicates significance at the $1 \%$ level.

Source: Authors' estimations

It is employed panel unit root tests since the cumulative sums for each cross-section require ensuring both the series are nonstationary in the Hatemi-J's causality approach. The results of unit root tests for the series are shown in Table 4. According to Table 4, the null hypothesis of a unit root cannot be rejected at the $1 \%$ significance level in their levels, while the null hypothesis of a unit root can be strongly rejected for the first-difference of both variables.

Table 4. Results for Unit root

\begin{tabular}{|c|c|c|c|c|c|c|}
\hline & \multicolumn{2}{|c|}{ IPS } & \multicolumn{2}{|c|}{ MW } & \multicolumn{2}{|c|}{ Choi } \\
\hline Variable & Stat. & P-value & Stat. & P-value & Stat. & P-value \\
\hline FR & $-0,232$ & 0,408 & 11,354 & 0,330 & 12,013 & 0,284 \\
\hline $\mathrm{CC}$ & 0,340 & 0,633 & 10,599 & 0,389 & 8,153 & 0,613 \\
\hline$\Delta F R$ & $-5,331 * * *$ & 0,000 & $44,824 * * *$ & 0,000 & $40,621 * * *$ & 0,000 \\
\hline$\Delta \mathbf{C C}$ & $-7,845^{* * *}$ & 0,000 & $65,610 * * *$ & 0,000 & $64,000 * * *$ & 0,000 \\
\hline
\end{tabular}

$\Delta$ is the first difference operator. The maximum lag lengths were set to 3 and Schwarz Bayesian Criterion was used to determine the optimal lag length. $* * *$ denotes the rejection of the null at the $1 \%$ significance level.

Finally, the nonasymmetric causality test results are reported in Table 5. According to the empirical results, the null hypothesis of positive/negative shocks not causing 
positive/negative financial risk shocks can be strongly rejected for Ireland. In addition, the results showed that a positive shock in climate change cause a negative shock in financial stability for Italy. Moreover, when analyzed the asymmetric causal relationships between financial risk and climate change for Spain, the null hypothesis of negative shocks in climate change not causing any financial risk shocks can be rejected. In the cases of Greece and Portugal none of the hypothesis can be rejected. So, these results suggest that climate change is an important factor in maintaining of financial stability for the economies of Ireland, Italy and Spain.

Table 5. Results for Asymmetric Panel Causality Test

\begin{tabular}{|c|c|c|c|}
\hline Countries & Null Hypothesis & M-Wald stat. & P-value \\
\hline \multirow[t]{4}{*}{ Greece } & $C C^{+} \not>F R^{+}$ & 0,016 & 0,899 \\
\hline & $C C^{+} \neq>F R^{-}$ & 0,011 & 0,915 \\
\hline & $C C^{-} \neq>F R^{-}$ & 0,947 & 0,330 \\
\hline & $C C^{-} \neq>F R^{+}$ & 0,534 & 0,465 \\
\hline \multirow[t]{5}{*}{ Ireland } & Null Hypothesis & M-Wald stat. & P-value \\
\hline & $C C^{+} \neq>F R^{+}$ & $8,730 * * *$ & 0,003 \\
\hline & $C C^{+} \neq>F R^{-}$ & 0,671 & 0,413 \\
\hline & $C C^{-} \neq>F R^{-}$ & $29,517 * * *$ & 0,000 \\
\hline & $C C^{-} \neq>F R^{+}$ & 0,061 & 0,805 \\
\hline \multirow[t]{5}{*}{ Italy } & Null Hypothesis & M-Wald stat. & P-value \\
\hline & $C C^{+} \neq>F R^{+}$ & 0,811 & 0,368 \\
\hline & $C C^{+} \neq>F R^{-}$ & $3,510 *$ & 0,061 \\
\hline & $C C^{-} \neq>F R^{-}$ & 0,012 & 0,913 \\
\hline & $C C^{-} \not>F R^{+}$ & 1,603 & 0,206 \\
\hline \multirow[t]{5}{*}{ Portugal } & Null Hypothesis & M-Wald stat. & P-value \\
\hline & $C C^{+} \not>F R^{+}$ & 0,238 & 0,626 \\
\hline & $C C^{+} \neq>F R^{-}$ & 0,290 & 0,590 \\
\hline & $C C^{-} \neq>F R^{-}$ & 0,440 & 0,507 \\
\hline & $C C^{-} \not>F R^{+}$ & 0,376 & 0,540 \\
\hline \multirow[t]{5}{*}{ Spain } & Null Hypothesis & M-Wald stat. & P-value \\
\hline & $C C^{+} \not>F R^{+}$ & 0,001 & 0,976 \\
\hline & $C C^{+} \neq>F R^{-}$ & 0,813 & 0,367 \\
\hline & $C C^{-} \neq>F R^{-}$ & $3,497 *$ & 0,061 \\
\hline & $C C^{-} \neq>F R^{+}$ & $9,628 * * *$ & 0,002 \\
\hline
\end{tabular}

The vector $\left(C C^{+}, F R^{+}\right)$signifies the cumulative positive shocks and $\left(C C^{-}, F R^{-}\right)$represents the cumulative negative shocks. $* * * *$ indicate significance at the $1 \%$ and $10 \%$ levels, respectively.

Source: Authors' estimation

We also estimate the relationship among energy used in agriculture and forestry and financial risk using panel least squares estimator. The results of panel estimation are summarized in Table 6. According to Table 6, energy used in agriculture and forestry as a proxy variable of climate change has statistically significant and negative effect on financial stability in the PIIGS countries. So, we can say that greater energy used in agriculture and forestry decreases financial stability. 
Table 6. Results for Panel Least Squares Method

\begin{tabular}{|c|c|c|c|c|}
\hline \multicolumn{5}{|c|}{ Dependent Variable: D(FR) } \\
\hline \multicolumn{5}{|c|}{ Method: Panel EGLS (Cross-section weights) } \\
\hline \multicolumn{5}{|c|}{ White cross-section standard errors \& covariance (d.f. corrected) } \\
\hline Variable & Coefficient & Std. Error & t-Statistic & Prob. \\
\hline $\mathrm{D}(\mathrm{CC})$ & $-1.614596 * * *$ & 0.530311 & -3.044622 & 0.0031 \\
\hline $\mathrm{C}$ & 0.537322 & 0.348079 & 1.543677 & 0.1263 \\
\hline$@$ trend & $-0.075086 * *$ & 0.029996 & -2.503205 & 0.0142 \\
\hline
\end{tabular}

$\mathrm{D}$ is first difference operator. $* * * * *$ indicate significance at the $1 \%$ and $5 \%$ levels, respectively. Source: Authors' estimation

\section{CONCLUSION}

Climate change is an increasingly prominent issue on the agenda of institutional investors, policy makers. The underlying of this prominent issue is that there have been two reasons. The first one is that financial institutions appear to increasingly respond to the broader societal challenge to realize the transition to a low-carbon economy. The second is that there is increasing awareness of the potential related financial risks, especially those resulting from being high-carbon as the economy transitions to a low-carbon world.

This study focused on the relationship between financial risk and energy used in agriculture and forestry as a proxy variable of climate change. In order to perform this, using asymmetric panel causality test suggested by Hatemi-J (2011), the findings of the study showed that the null hypothesis of positive/negative shocks not causing positive/negative financial risk shocks can be strongly rejected for Ireland. In addition, the results showed that a positive shock in climate change cause a negative shock in financial stability for Italy. When analyzed the asymmetric causal relationships between financial risk and climate change for Spain, the null hypothesis of negative shocks in climate change not causing any financial risk shocks can be rejected. For Greece and Portugal none of the causal relationships cannot be proved. So, these results suggest that climate change is an important factor in maintaining of financial stability for the economies of Ireland, Italy and Spain.

So, climate change risk represents a threat to the stability of global financial markets. Especially, if changing climate conditions are not actively and effectively managed, investments and institutions may underperform. Hence, international financial regulators as well as governments have important roles in managing climate change risks. For instance, international financial regulators should standardize mandatory climate change risk disclosure. Moreover, the countries may seek political support for strengthening climate change regulations. In addition, international financial regulators should establish research on strategies reduce uncertainty in assessing the financial risks occurred by climate change (Thistlethwaite 2015). 


\section{REFERENCES}

ABI, the Association of British Insurers (2005). Financial Risks of Climate Change, June 2005, Summary Report, (15.12.2015)

https://www.cigionline.org/sites/default/files/policy_brief_no.62.pdf>

BIS, Bank for International Settlements, (2001). Group of Ten-Consolidation in Financial Sector, (15.12.2015), <://www.bis.org/publ/gten05ch3.pdf >

BREUSCH, T. S. and PAGAN, A. R. (1980). The Lagrange Multiplier Test and its Applications to Model Specification in Econometrics, The Review of Economic Studies, Vol. 47, No. 1, Econometrics Issue, pp. 239-253.

CHENET, Hugues., JAKOB Thomä, DIDIER Janci. (2015). Financial Risk and the Transition to a Low Carbon Economy Towards A Carbon Stress testing Framework, $2^{\circ}$ Investing Initiative Working Paper July 2015.

CHOI, I. (2001). Unit root tests for panel data. Journal of International Money and Finance 20: 249-272.

DAILEY, Peter., Matt Huddleston, Simon Brown and Dennis Fasking (2009). The Financial Risks of Climate Change, ABI Research Paper No 19, 2009.

Food and Agriculture Organization of the United Nations, FAOSTAT, (2014).

GRANGEr, Clive W.J., Yoon, Gawon. (2002). "Hidden Cointegration," Royal Economic Society Annual Conference 2002 92, Royal Economic Society.

HATEMI-J, A. (2011). Asymmetric Panel Causality Tests with an Application to the Impact of Fiscal Policy on Economic Performance in Scandinavia. MPRA Paper No 55527.Munich: University Library of Munich.

HATEMI-J, A. (2012). Asymmetric Causality Tests with an Application. Empirical Economics, $43,447-456$.

HATEMI-J, A., Rangan Gupta, Axel Kasongo, Thabo Mboweni, Ndivhuho Netshitenzhe. (2014). Are there Asymmetric Causal Relationships between Tourism and Economic Growth in a Panel of G-7 Countries?, University of Pretoria, Department of Economics Working Paper Series, Working Paper: 2014-76.

IM, K.S., PESARAN, M. H. and SHIN,Y., (2003). Testing for Unit Roots in Heterogeneous Panels. Journal of Econometrics, 115, pp.53-74.

MADDALA, G. S. \& WU, Shaowen. (1999). A Comparative Study of Unit Root Tests with Panel Data and a New Simple Test. Oxford Bulletin of Economics and Statistics, Special Issue, 0305-9049: 631-652.

PESARAN, M.H. (2006), Estimation and Inference in Large Heterogeneous Panels with a Multifactor Error Structure", Econometrica, 74(4), 967-1012.

PESARAN MH, Yamagata T (2008). "Testing slope homogeneity in large panels". Journal of Econometrics 142: 50-93.

PRS Group (2005). About ICRG: The Political Risk Rating, <http://www.icrgonline.com/page.aspx?page=icrgmethods $>$.

STENEK, Vladimir, Jean Christophe Amado, Richenda Connell. (2009). Climate Risk and Financial Institutions, Challenges and Opportunities, International Finance Corporation, World Bank.

THISTLETHWAITE, J. (2015). The Challenges of Counting Climate Change Risks in Financial Markets. The Centre for International Governance Innovation Policy Brief, No. 62, June 2015. 